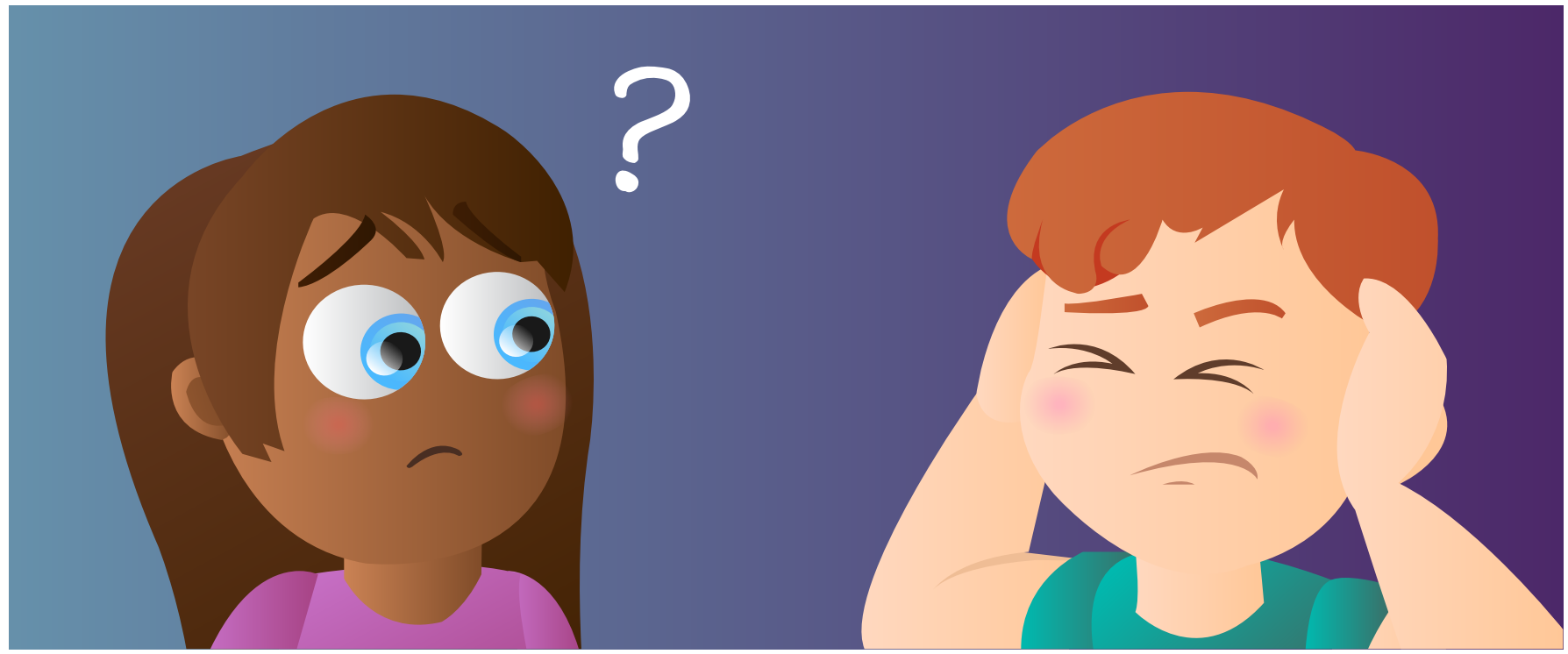

\title{
WHAT DOES TINNITUS HAVE TO DO WITH HEARING LOSS?
}

\section{Winfried Schlee ${ }^{*}$ and Giriraj Singh Shekhawat ${ }^{2}$}

${ }^{1}$ Department of Psychiatry and Psychotherapy, University of Regensburg, Regensburg, Germany, ${ }^{2}$ Section of Health Systems/Audiology, University of Auckland, Auckland, New Zealand

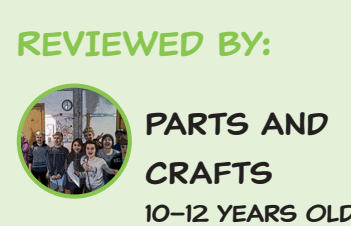

Our sense organs, along with our brains, give us a detailed understanding of the world around us. If something goes wrong with any of the sense organs, it will affect our everyday functioning. An example of this is hearing loss and tinnitus. Hearing loss is defined as the loss of auditory (sound) information due to damage to the hearing system. Tinnitus is a sound that people can hear, but there is nothing around them that is generating this sound. It can occur as a result of hearing loss. People describe tinnitus as a ringing, buzzing, or hissing sound, but there is no object around that is creating this sound. In this article, we describe some strategies that can be used to protect our hearing, such as moving away from the sound source, protecting the ears, and reducing the volume levels of the soundproducing devices. There is no cure for tinnitus yet. We also discuss ways to manage tinnitus, such as educating yourself about tinnitus, relaxation, focusing your attention away from tinnitus, and seeking the help of a doctor.

\section{HOW DO WE EXPERIENCE THE WORLD AROUND US?}

Our sense organs (eyes, ears, tongue, nose, skin) are extremely valuable in giving us a detailed picture of the world around us. To give an example, 


\section{HEARING LOSS}

Damage to the ear which results in reduced hearing ability.

\section{TINNITUS}

Hearing a sound that nobody else can here.

\section{FIGURE 1}

A. An example how our hearing can protect us while we are playing. B. You should read this figure from left to right. On the left side, you see how the sound enters the outer ear. It travels through the middle to the inner ear where it is transformed into electrical signals. The auditory nerve transmits the electrical impulses to the brain (right side). imagine you have an apple in your hand. You can touch it and feel its shape, you can see it with your eyes and tell its color, you can bite it and hear the crunch, enjoy its sweet flavor with your tongue, and smell it. Our sense organs send all this information to the brain, which then gives us a complete experience of enjoying the apple.

Each of these sensory organs is valuable to our everyday living and our mighty brain is the center of it all. The brain combines all this sensory information so that we can have a complete experience of the world.

\section{WHAT IF ONE OF THE SENSE ORGANS IS DAMAGED?}

Imagine what will happen if one of these sense organs gets damaged. Would we be able to enjoy the full experience of the world around us? Probably not, because now our brain would be missing the important information from this sense organ. We will be explaining this in detail by using the ear as an example. If our ears are damaged and we are not hearing well, this will have two consequences. First of all, the brain will be missing the information from the ears. This is called "hearing loss." Second, the brain tries to fill the gap created by this hearing loss. As a result of this, a person with hearing loss might start hearing a sound that others can't hear. This sound is called "tinnitus." We will explain both "hearing loss" and "tinnitus" in detail in this article.

\section{HEARING LOSS}

Our hearing is valuable for getting information about our environment and for communicating well with the people around us. We can hear our loved ones' voices or music, which makes us feel happy and creates positive emotions. Hearing can also play an important role in protecting us from danger. For example, look at the boy playing with a ball in the top panel of Figure 1 . A car is approaching toward him from the back. Even without seeing it, he instantly recognizes the sound of the car, knows the direction it is coming from, and has a chance to move out of the way.

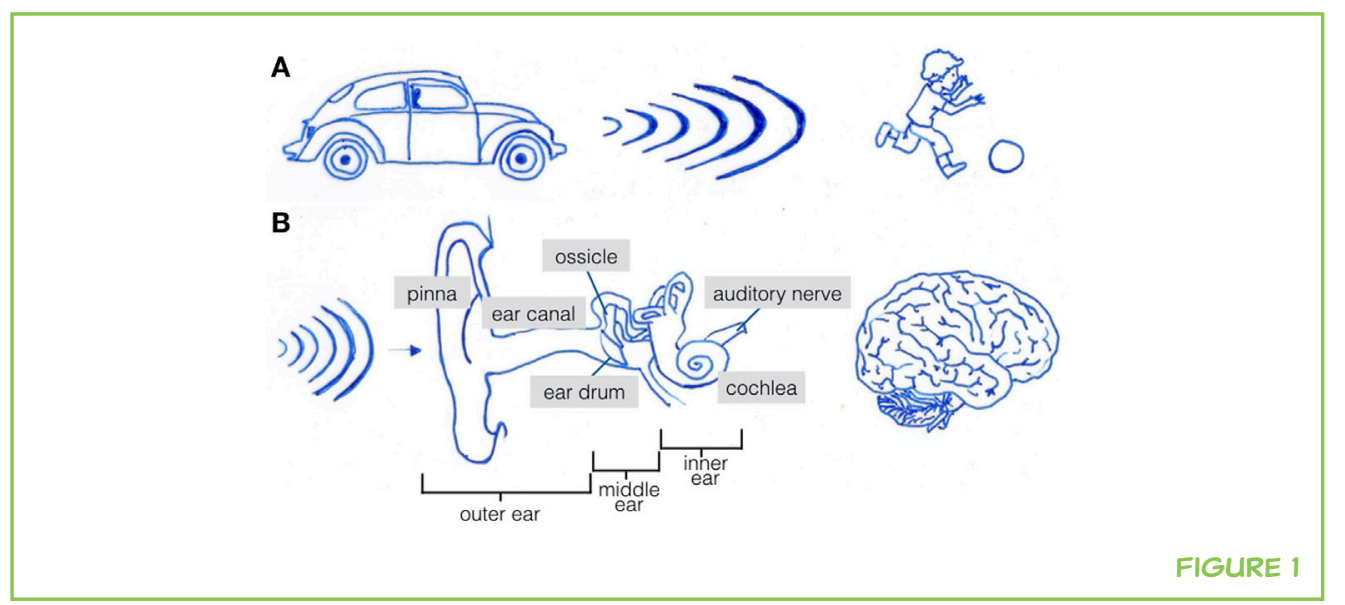




\section{COCHLEA}

The organ which lies in the inner ear and converts the sound into electrical signals.

\section{AUDITORY NERVE}

The nerve which sends auditory signals from our ears to the brain.

The bottom panel of Figure 1 explains how our hearing works. The sound is funneled through the outside of the ear, which is called the pinna, into the ear canal. These two parts are called the outer ear. The sound then vibrates the ear drum, which in turn sets the ossicles (a set of three tiny bones in the middle ear) in motion. This motion of the ossicles creates waves in the fluid of the snail-shaped cochlea. The cochlea is located deep inside, in an area called the inner ear. The cochlea is the place where the sound energy is converted into electrical impulses by thousands of tiny hair cells. The auditory nerve passes this information to the brain, where the details of the sound such as its characteristics, pitch, loudness, and direction, are then understood, so that the boy recognizes the sound of the engine as a car approaching from behind him. This is a rapid process that happens in less than a second. The speed of the hearing process allows the boy to quickly react.

Our hearing system, especially the hair cells in the inner ear, is very sensitive and can easily be damaged by loud sounds. Once these hair cells are damaged, the damage is permanent. Examples of these loud noises could be construction work, traffic noise, airplane engine noise, and others-but also could be pleasurable sounds such a TV at a very loud volume, loud music at a concert, or sound from i-pods, mp3 players, radios, or other music devices. It is extremely important to protect our ears from these loud noises, as they can permanently damage our hearing.

\section{HOW CAN YOU PROTECT YOUR EARS?}

You can use the following three strategies to protect your ears [1]. These strategies are also shown in Figure 2.

\section{STRATEGY 1: MOVE AWAY FROM THE SOUND SOURCE}

If possible, you should try to move away from loud sounds. For example, if there is construction work happening and it produces very loud noises, you can quickly walk away from it. To give you another example, imagine that you are in an auditorium standing next to a loudspeaker and you feel that it is too loud. You can choose to move away from the speaker. Moving away from the source of the sound reduces the impact of these loud sounds on your ears and minimizes the chances of damaging your hearing.

\section{STRATEGY 2: PROTECT YOUR EARS}

In some situations, it is not possible to move away from the sound source, but you can still protect your ears. If you have ear muffs or ear plugs, you should use them to protect your hearing. This is what many people do when they have to work in loud environments-they carry a professional ear protection device and use it when there are loud sounds. Or, if you don't have such an ear protection device, you can simply cover your ears with your hands. Even better, you can put your index fingers in your ear canals to block the sound from getting into the ear. 


\section{FIGURE 2}

Three strategies to protect our ears from the effects of very loud sounds.

\section{How can we protect our ears?}
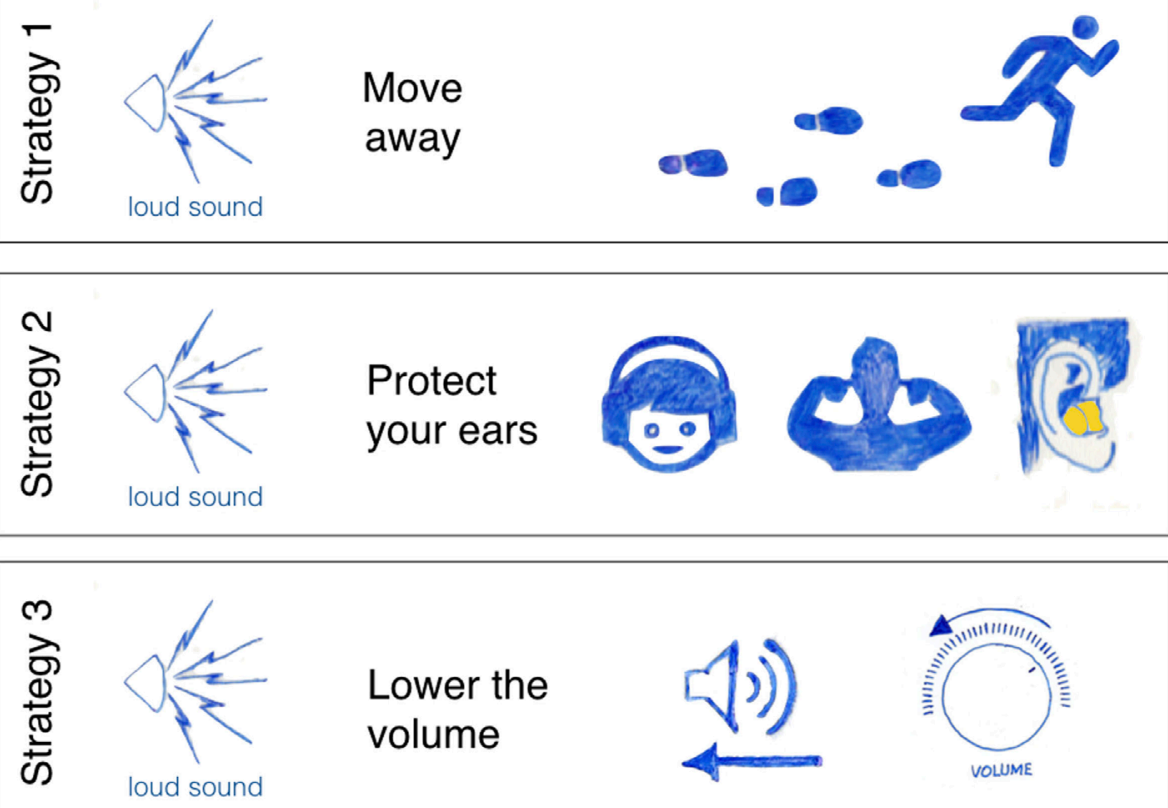

FIGURE 2

\section{STRATEGY 3: LOWER THE VOLUME}

When you are listening to music or watching TV, you should keep an eye on the sound level. If you are listening to loud music or TV for a long time, this can lead to permanent damage to your hearing. Sometimes, video games and electronic toys come with high sound levels and don't have a switch to turn the sound down. In this case, you can cover the loudspeaker with several layers of tissue to absorb the sound and reduce the volume.

All these strategies can help you to prevent damage to the ear and preserve your hearing. If you pay attention to professional musicians, many of them wear ear plugs while they are performing on stage because they want to protect their precious hearing, which is extremely important for a good musician.

\section{TINNITUS}

Tinnitus is a symptom that can develop as a result of hearing loss. If you have tinnitus you will be hearing a sound but there will be no object around you which is creating that sound. This tinnitus happens because the brain is trying to make up for the lack of input from the ear due to the hearing loss.

Tinnitus is a very common condition affecting millions of people worldwide [2]. Most often, people with tinnitus describe it as a ringing sound or a noise like buzzing, whistling, or hissing. It is very likely that you have heard a tinnitus sound yourself for a very short period of time, for example, after 
attending a loud concert or after exposure to a sudden loud noise such as a loud hammer sound. If you have this brief tinnitus, don't be afraid-for most people it will disappear on its own. However, for some people it does not go away and they hear this tinnitus sound constantly, which is irritating to them. Some of these people are bothered by their tinnitus so much that they find it hard to fall asleep, they find it difficult to concentrate, or they have problems following a conversation because they hear the tinnitus all the time. Some of them even feel anxious or depressed and it can affect their quality of life.

\section{WHAT DO RESEARCHERS THINK ABOUT TINNITUS?}

Tinnitus means hearing an extra sound, so it's easy to make an assumption that it is a problem of the ear. This is what the researchers thought many years ago. However, in the past few decades, many researchers have studied brain scans that record activity in different parts of the brain. These researchers have realized that tinnitus is not only the problem of the ear, but there are different areas in the brain that are involved in tinnitus as well [3]. Scientists all over the world are working every day toward gaining a better understanding of tinnitus and our knowledge about this condition has been improving every year. These scientists meet every year at conferences and meetings, for example, the "Tinnitus Research Initiative," "International Tinnitus Seminar," and "TINNET," to discuss the latest findings in the area of tinnitus. There are several specialized clinics dedicated to helping people with tinnitus and several ways to manage tinnitus, which have been developed for people who suffer from this condition.

\section{WHAT CAN BE DONE FOR TINNITUS?}

There is currently no cure for tinnitus, but there are several ways to manage it or partly reduce it $[4,5]$. Here are some useful tips for managing tinnitus. Feel free to share some of these with people you know who have tinnitus.

1. Know your tinnitus - it is important to understand tinnitus, its causes, and what can be done to manage it. This information can be valuable in dealing with tinnitus and correcting the wrong beliefs associated with it. It is important to understand that tinnitus is not a sign of danger, it is a non-threatening sound and there is no need to be afraid of it.

2. Relaxation and distraction-some people with tinnitus experience that it is reduced when they are relaxed, so it is good to reduce stress. This can be achieved by using relaxation techniques such as deep breathing, walking, sport activities, doing enjoyable things, or any other activities which can be relaxing. Some people also benefit from focusing their attention away from tinnitus by doing things like listening to soothing music or doing something interesting. When they aren't focusing on the tinnitus, it can make it less bothersome. 


\section{AUDIOLOGISTS}

Hearing expert, who deals with people with hearing loss, does hearing aid fitting, and management of hearing loss.
3. Seek professional help-besides the hearing loss described in this article, there can be several other causes of tinnitus. Some medical professionals are trained to help people with tinnitus. Those experts include ear/ nose/throat doctors, audiologists (hearing experts), neurologists (brain experts), psychologists, and physical therapists. These professionals can offer several management options based on the details of the tinnitus and the other symptoms the patient might be having. Examples of these management options are hearing aids, devices called maskers that "cover up" the sound of the tinnitus, counseling to learn how to deal with the tinnitus, and brain stimulation - to name just a few. It is also important to remember that every person with tinnitus is unique and everyone responds differently to the types of treatment offered. Therefore, it is extremely important to get professional help. The tinnitus experts can help find the best treatments to reduce the tinnitus.

\section{REFERENCES}

1. Martin, W. H. 2008. Dangerous decibels: partnership for preventing noise-induced hearing loss and tinnitus in children. Seminars in Hearing. Stuttgart: Thieme Medical Publishers.

2. Shargorodsky, J., Curhan, G. C., and Farwell, W. R. 2010. Prevalence and characteristics of tinnitus among US adults. Am. J. Med. 123:711-718. doi:10.1016/j.amjmed.2010.02.015

3. De Ridder, D., Elgoyhen, A. B., Romo, R., and Langguth, B. 2011. Phantom percepts: tinnitus and pain as persisting aversive memory networks. Proc. Natl. Acad. Sci. U.S.A. 108:8075-8080. doi:10.1073/pnas.1018466108

4. Langguth, B., Kreuzer, P. M., Kleinjung, T., and De Ridder, D. 2013. Tinnitus: causes and clinical management. Lancet Neurol. 12:920-930. doi:10.1016/S14744422(13)70160-1

5. Baracca, G., Del Bo, L., and Ambrosetti, U. 2011. Tinnitus and hearing loss. In: Møller AR, Langguth B, De Ridder D, Kleinjung T, editors. Textbook of Tinnitus. New York: Springer. p. 285-291.

SUBMITTED: 01 July 2016; ACCEPTED: 09 February 2017; PUBLISHED ONLINE: 24 February 2017.

EDITED BY: Fulvio D’Acquisto, Queen Mary University of London, UK

CITATION: Schlee W and Shekhawat GS (2017) What Does Tinnitus Have to Do with Hearing Loss? Front. Young Minds 5:2. doi:10.3389/frym.2017.00002

CONFLICT OF INTEREST STATEMENT: The authors declare that the research was conducted in the absence of any commercial or financial relationships that could be construed as a potential conflict of interest.

COPYRIGHT () 2017 Schlee and Shekhawat. This is an open-access article distributed under the terms of the Creative Commons Attribution License (CC BY). The use, distribution 
and reproduction in other forums is permitted, provided the original author(s) or licensor are credited and that the original publication in this journal is cited, in accordance with accepted academic practice. No use, distribution or reproduction is permitted which does not comply with these terms.

\section{REVIEWED BY}

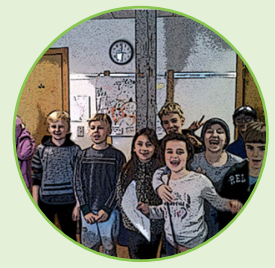

\section{PARTS AND CRAFTS, 10-12 YEARS OLD}

Why do some fires burn blue and others burn red, green, or orange? Do sensory deprivation chambers really work? What makes leaves change color? Each week we'll pick a different question, run a demo or experiment, and try to answer it with our own observations. www. partsandcrafts.org.

\section{AUTHORS}

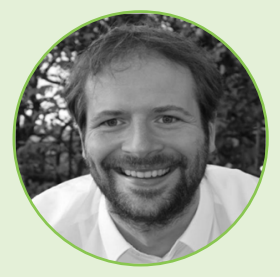

\section{WINFRIED SCHLEE}

I am a tinnitus researcher at the University Hospital of Regensburg in Germany. I love to do research. It is great to try out new things that nobody else has done before, and thereby learn a lot of things about the brain and about tinnitus. I am the scientific coordinator of the Tinnitus Research Initiative (TRI), which means that I can work in a great team that is doing research projects on tinnitus all over the world. My big goal is that we find a cure for tinnitus so that nobody in the world needs to suffer from it anymore. *winfried.schlee@gmail.com

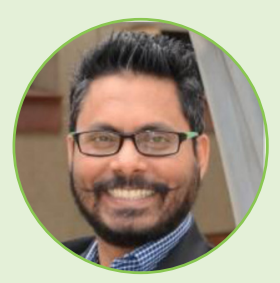

\section{GIRIRAJ SINGH SHEKHAWAT}

I am a clinical audiologist working with people with hearing loss and tinnitus for over 10 years. I love teaching and research. I have worked in many different countries such as USA, India, Singapore, and now I am settled in New Zealand. I work for the University of Auckland in the section of Health System and Audiology. My passion lies in researching tinnitus and ways to manage this condition. I am public relations manager for "Tinnitus Research Initiative," which gives me cool opportunities to interact with tinnitus researchers from the entire world. girirajss@gmail.com 